\title{
ALTERED EXPRESSION OF CARTILAGE OLIGOMERIC MATRIX PROTEIN IN PSORIASIS
}

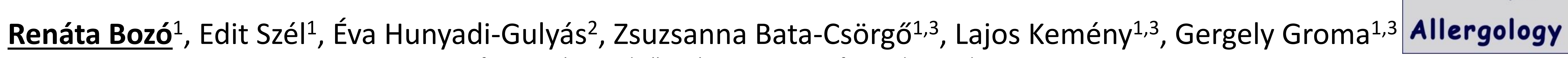
1 Department of Dermatology and Allergology, University of Szeged, Szeged, Hungary

2 MTA Biological Research Center, Proteomic Research Group, Szeged, Hungary

3 MTA-SZTE Dermatological Research Group, University of Szeged, Szeged, Hungary

\section{BACKGROUND}

In a large scale psoriatic proteomic approach where non-lesional, lesional and healthy skin were compared, the protein level of cartilage oligomeric matrix protein (COMP) was found to be elevated in the non-lesional $(\mathrm{NL})$ skin $(3,6 \mathrm{x})$. Since the psoriatic uninvolved skin of patients is more sensitive to mechanical stress and COMP has a mechanoresponsive region in its promoter and can interact with several proteins proposed to influence inflammation and keratinocyte proliferation including $\alpha 5 \beta 1$ integrin and fibronectin, therefore we aimed to characterize the observed difference further.

\begin{tabular}{|c|c|}
\hline $\begin{array}{l}\text { Interaction with integrins } \\
\left(\alpha_{5} \beta_{1} \alpha_{v} \beta_{3}, \alpha_{7} \beta_{1}\right) \\
\text { cell proliferation } \\
\text { cell survival }\end{array}$ & $\begin{array}{l}\text { Interaction with integrins } \\
\left(\alpha_{5} \beta_{1} \alpha_{v} \beta_{3}, \alpha_{7} \beta_{1}\right) \\
\text { cell migration } \\
\text { cell implantation }\end{array}$ \\
\hline $\begin{array}{l}\text { Interaction: COLI, COLIII, COLXII, Collagen fibril } \\
\text { COLXIV, aggrecan, fibronectin } \begin{array}{c}\text { COLII, } \\
\text { formation and stabilization } \\
\text { of ECM network }\end{array}\end{array}$ & $\begin{array}{l}\text { genesis (COLI, } \\
\text { OLIII) }\end{array}$ \\
\hline
\end{tabular}

Figure 1. Major known interactions and functions of COMP

\section{MATERIALS AND METHODS}

- Skin biopsies: Patients with moderate-to-severe chronic plaque type psoriasis and healthy volunteers were enrolled into the study. Patients had a medication-free period of at least 4 weeks of systemic and/or at least 2 weeks without local therapy. Samples were collected from lesional skin and from non-lesional skin from at least $6 \mathrm{~cm}$ far from the lesion and from healthy volunteers.

- Immunofluorescent stainings: primary antibodies: rabbit polyclonal Ab for COMP, mouse polyclonal $A b$ for $\beta 1$ integrin, secondary antibodies: goat anti-rabbit IgG-Alexa Fluor 546, goat anti-mouse IgG-Alexa Fluor 647.

- Western blot: primary antibody: goat polyclonal Ab for COMP, secondary antibody: donkey anti-goat IgG-AP.

\section{AIMS}

1. To verify the proteomic results by immunofluorescence stainings and Western blot. We aimed to characterize COMP in the context of psoriasis

2. To investigate if COMP could potentially influence basal keratinocytes by direct interaction, COMP was co-stained with $\beta 1$ integrin.

\section{RESULTS 1/A}

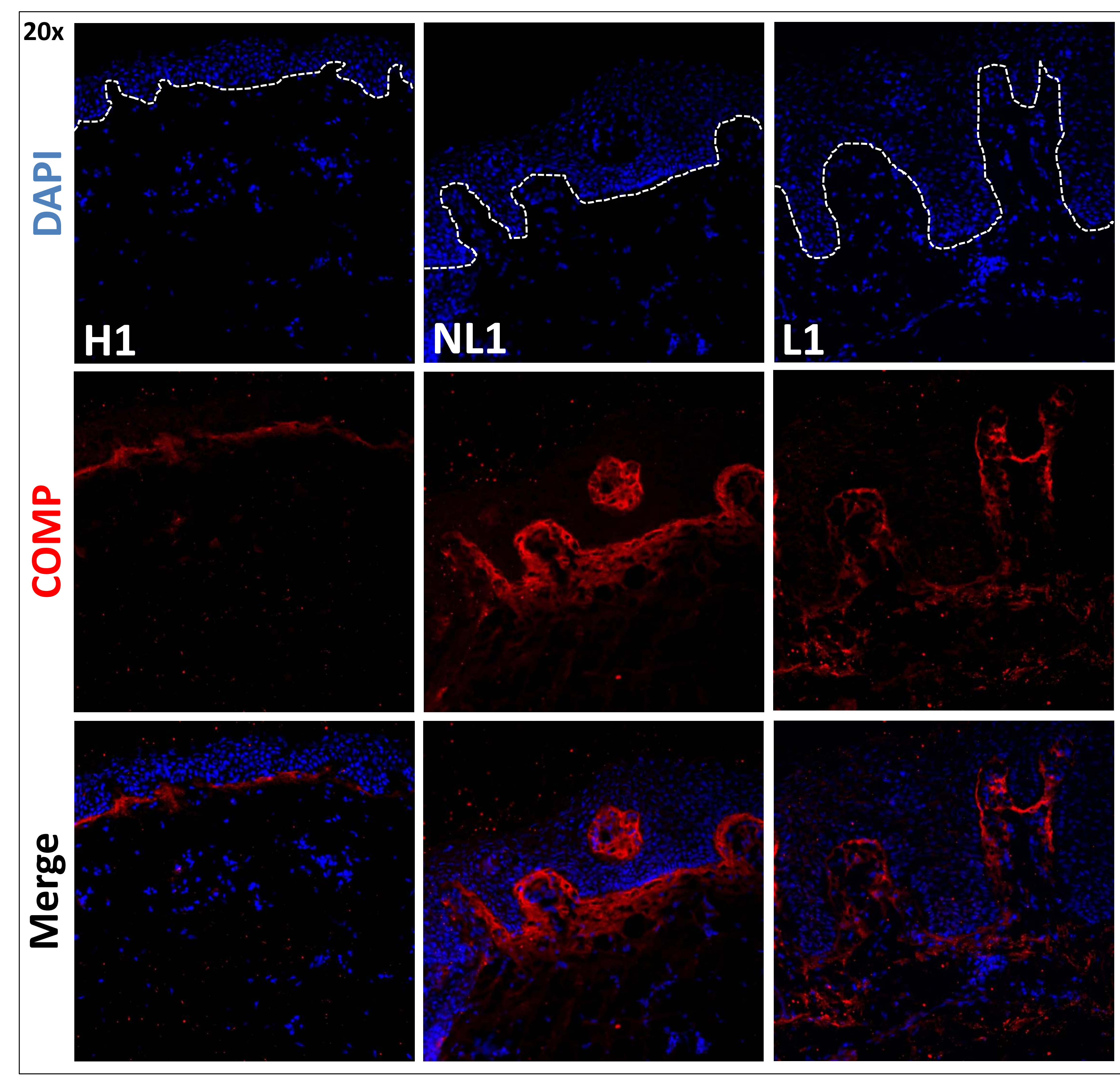

Figure 2. COMP deposition is more pronaunced in NL and L skin compared to healthy controls.

\section{REFERENCES}

Agarwal,et al, Journal of Biological Chemistry, 2012

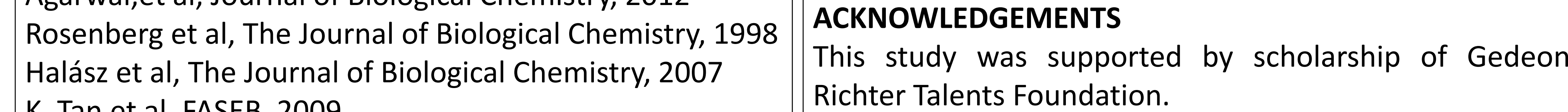
K. Tan et al, FASEB, 2009

Agarwal et al, Matrix Biology, 2013

\section{RESULTS 1/B}

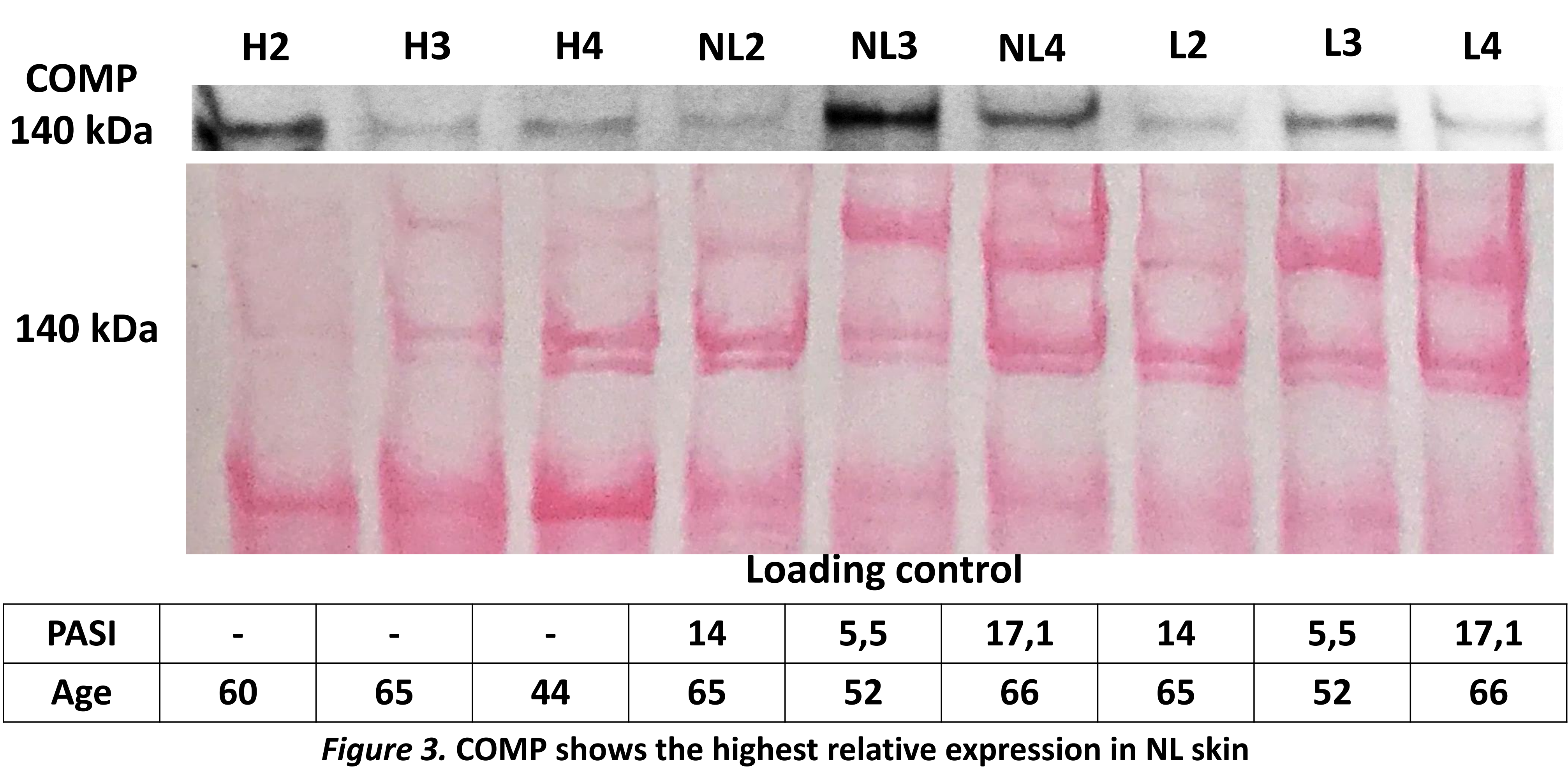

RESULTS 2.
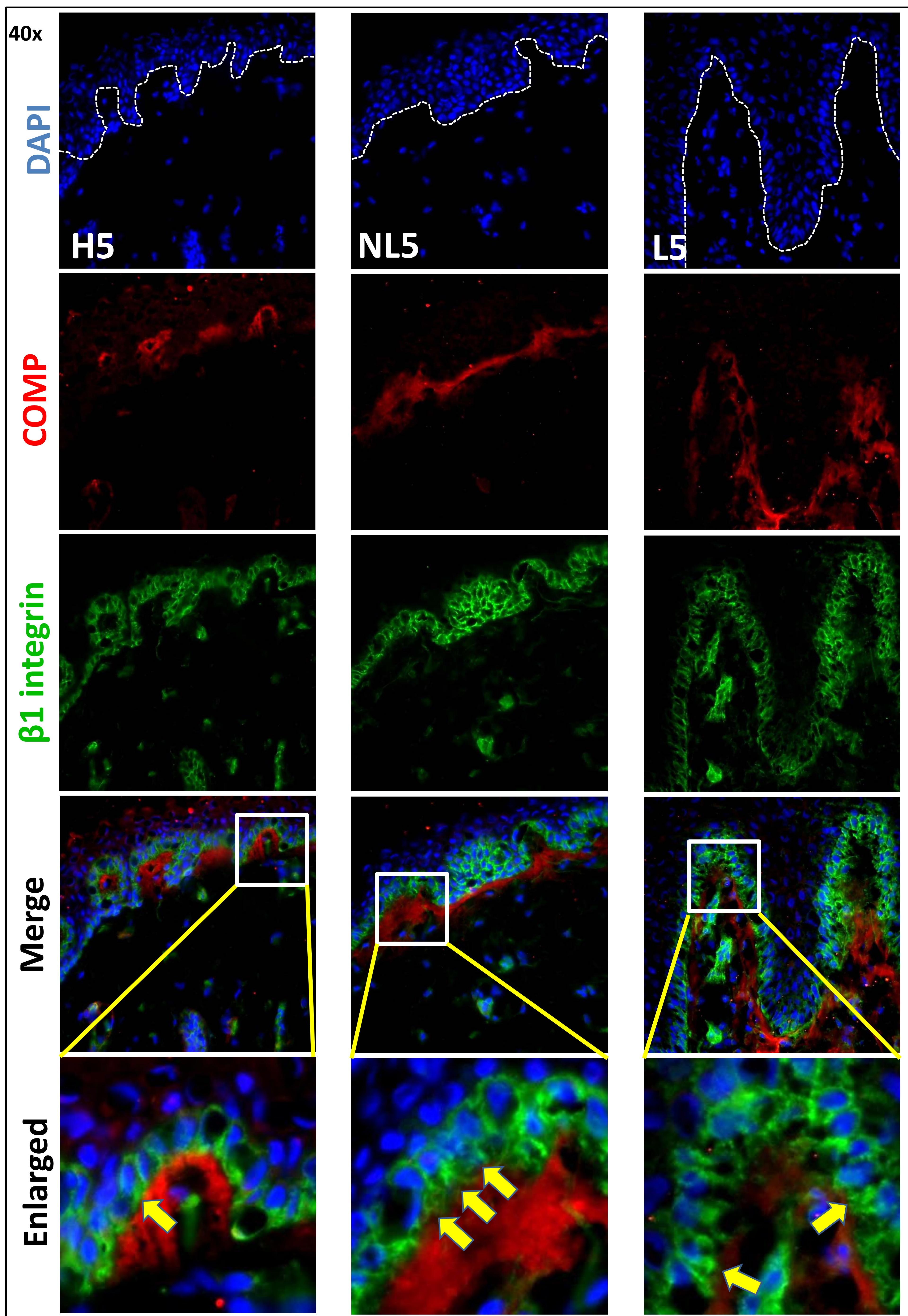

Figure 4. COMP colocalized with $\beta 1$ integrin in all skin samples $(\mathrm{H}, \mathrm{NL}, \mathrm{L})$, but it was most frequent in $\mathrm{NL}$

\begin{tabular}{|c|c|c|c|c|}
\hline PASI-AGE/patients & H1 & H5 & NL1/L1 & NL5/L5 \\
\hline PASI & - & - & 22,4 & 12 \\
\hline Age & 51 & 37 & 49 & 55 \\
\hline
\end{tabular}

\section{SUMMARY \& CONCLUSION}

Western blot (4 out of 6) and immunofluorescent results (8 out of 10) reflect the outcome of our proteomic approach. COMP showed the highest relative amount in the non-lesional skin. The keratinocyte proliferation of the psoriatic skin shows some similarities to wound healing and our results are well in line with a previous report indicating that in non-healing wounds the level of COMP is elevated while in healing wounds the amount of COMP is minimal. Our results showed that COMP to some extent colocalized with $\beta 1$ integrin positive basal keratinocytes in all three skin types, but the joint occurrence of the two protein was the most frequent in non-lesional skin and the lowest in the lesional skin. Therefore, we conclude that COMP may directly interact with basal keratinocyte and it may influence keratinocytes proliferation in psoriasis. 